\title{
ECONOMIC CULTURE OF UKRAINE IN THE CONTEXT OF EUROPEAN INTEGRATION
}

\author{
Pavlo Lepak ${ }^{1}$ \\ pavel_lepak@ukr.net \\ Larysa Kulish ${ }^{1}$ \\ larysa.kulish2018@knute.edu.ua \\ ${ }^{1}$ Department of Economics and Competition Policy \\ Kyiv National University of Trade and Economics \\ 19 Kyoto str., Kyiv, Ukraine, 02156
}

\begin{abstract}
Condition research of economic culture of Ukraine in the context of European integration is fundamental for the formation of effective reforms and strategies of public administration and the need for further methodological improvement.

The theoretical and methodological basis of the article is the scientific research of scientists and reports of international organizations, in particular the condition research of world values, conducted as part of the research "World values Survey" (WVS), in the period 2017-2020.

General approaches and research methods were used during the preparation of the article: theoretical generalization, analysis, synthesis and system method, statistical research, sociological research and expert opinions.

The use of these methods allowed to consider the current position of economic culture and entrepreneurial culture in the context of European integration, through the prism of economic values, which are empirically studied.

In this research, the author's determination of the state of economic culture in the transformation process was carried out.

Keywords: economic culture, European values, integration, modernization, entrepreneurial culture.
\end{abstract}

DOI: $10.21303 / 2504-5571.2021 .001571$

\section{Introduction}

Ukrainian society, as well as the whole world, met the COVID-19 epidemic as a large-scale stressor and a return to existential threats in the world. Restrictions, caused by quarantine, affected the economy and the well-being of the population, and as a result provoked public discontent. This affected economic culture and its transformation in the European integration process. New challenges and threats to Ukraine's future have been added to the complex processes of building democratic institutions, and the lack of systemic reforms, which is reflected in public distrust of state institutions and a lack of understanding of the vector of movement.

Europe is based on the values of freedom and democracy. These European values were formed during the Enlightenment and were proclaimed politically during the French Revolution. They are enshrined in the Charter of Human Rights of the Council of Europe and the Charter of Fundamental Rights of the European Union. The European Union is called a community of values, so the economic values of the countries that want to join are relevant. The Lisbon Treaty provides for many innovations, but one of the main achievements is the introduction of a new legal category - the category of values, which before the adoption of the treaty was mentioned only in doctrine, and after the Lisbon Treaty received legal expression. The use of the term "value" in the new version of the Treaty on European Union is intended to emphasize that European integration and the right, created within it, must comply with moral norms, and in no way contradict them.

Introducing the category of values, the legislator emphasizes the European Union's entry into a completely different level of development, in which the moral and ethical aspect acquires a decisive role along with the legal one. The values of the Union are directly linked to principles that are easy to see. The change in the order of mention of values in the new version of the Treaty on European Union indicates the growth of their significance for the Union. Values are higher levels, compared to the principles. They can even be considered as a source of principles of law. 
Each national economic culture is diverse and multilevel and includes many elements. However, in the foundations of economic culture it is possible to identify a small number of the most fundamental structures. Researchers often use the term value for them, which can be defined as the most common tendency to prefer a certain state of affairs over others, to consider it a good. These constructs are quite abstract and not always conscious, but they influence the choice of life goals and means of achieving them in various areas - from interpersonal relationships and approaches to raising children to the political system, religious views and economic relations.

The process of transformation of society is considered by many scientists. Lagytin V. examines through civilizational and institutional factors of global economic transformations [1]. In the categories of modernization of the societies of the post-Soviet states, scientists Mueller K. [2], Tiryakian E. [3] Cohen S. and consider categories of «demodernization» [4], when some countries returned to the vision of Soviet times. Savelyev Y. [5] considers that European integration with democratic societies, inclusive social institutions and innovation-oriented economics has proved to be a fairly effective strategy for modernizing the majority of post-socialist countries, but this is not the opposite of this, as evidenced by the de-modernization challenges of today.

The study of economic values allows government agencies to form an effective strategy for transforming society into the desired vector, and to identify obstacles in this way.

Aim of the study is to determine the condition of economic culture of Ukraine and to reveal the value orientations of Ukrainians, to give an economic assessment of the transformational process of economic culture of Ukraine, on the path to European integration.

\section{Materials and Methods}

The theoretical and methodological basis of the study is general scientific and special methods of scientific knowledge, the application of which made it possible to achieve the goal. The authors analyzed the behavioral aspects of economic relations through the prism of economic culture, while using the valuable reference points of society. The study used empirical methods of constructing a statistical research, sociological surveys and expert opinion.

This study uses statistical data, taken from WVS. The sample type, preferable for using in the World Values Survey, is a full probability sample of the population aged 18 years and older. Probability sampling is a sampling technique, wherein the samples are gathered in a process that gives all the individuals in the population equal chances of being selected. This study allows application of a national representative random sample, based on multi-stage territorial stratified selection.

Stratified sampling is a probability sampling technique, wherein the entire population is divided into different subgroups or strata, then randomly selects the final subjects proportionally to the population from the different strata. The main method of data collection is face-to-face interview at respondent's home / place of residence. Respondent's answers could be recorded in a PAPI (Paper Assisted Personal Interviews) or via CAPI (Computer Assisted Personal Interview).

The use of these methods allowed the authors to compare the economic values of society in the context of the following opinions:

- private versus state ownership of business breakdown by age

- government's vs individual's responsibility breakdown by settlement type

- competition good or harmful

Using the open data of the World Bank and expert assessment, the Indicator of the barrier to entry into the domestic market was compared to the conditions of development of entrepreneurial culture.

\section{Results}

At the turn of the century, economics is searching for the specifics of sociocultural implications for economic systems and is moving away from focusing on a single understanding of "rational human", which in turn expands the invention of optimal in terms of efficiency innovative models of economic transformation. Successful welfare experiences in some countries have not led to the same result of economic reform in others, leading to the understanding that the success of reforms is possible, where the basics of maximum utility fit into the archetype of national culture, where there is a clear correspondence transformation. 
Deepening knowledge of the social dimension of neutral interaction of subjects allows to justify the deep scale of values that shape the motives of behavior, economic interests and determine its life goals. In this case, the actual spiritual and moral values and motivations should determine the palette of decisions and actions of a human. That is why the need to move away from the traditional understanding of human as a biological and social being and the transition to awareness of the spiritual, biological, and social nature of human, in which the spiritual dimension is decisive, is justified. Decisive for a person are ideas, decisions and actions that follow from the deep values of knowledge of the world, which is constantly transforming, in which the human personality on the basis of its freedom and responsibility forms relationships with other actors.

Comparing the vectors of development of the former Soviet societies of Eastern Europe, noticeable differences become obvious. In particular, in the early 90's there was a demarcation of the Eastern European region and ways of its development. Countries, such as Belarus, Moldova and Ukraine have been influenced by post-Soviet values and the influence of Russia, while the socialist bloc and Baltic countries have joined the European vector and worldview of values. As a result, those involved in the European integration process soon recovered from the economic crisis.

Many economists consider the emergence of Ukraine's independence, after the collapse of the Soviet Union in the categories of modernization [2, 3]. These changes lead to the development of state institutions, following the example of Western, capitalist societies, and give impetus to the construction of a market economy, the formation of a solidary economic culture of society, with democratic rights and freedoms. To do this, post-communist countries needed to define a clear political and economic movement towards Europe. However, Eastern Europe has encountered hybrid (transitional) forms of capitalism in post-socialist countries. The deep economic and cultural crisis of the early 90's made it impossible to quickly modernize, and sometimes return to the "pre-modern" state [4]. An analysis of the development of former Soviet societies in Eastern Europe shows that Ukraine, Belarus, and Moldova have moved toward rapprochement with Russia, which has significantly slowed their recovery from the crisis, when the Baltic states and socialist blocs recovered more rapidly after the 1990s decline (indicator of the Human Development Index in 1990) [5]. Against the background of authoritarian regimes in Belarus and Russia and political instability in Moldova and Ukraine, European integration seemed to be an effective strategy for the modernization and development of post-socialist societies in Central and Eastern Europe.

Ukraine has gone through its historical path of finding and choosing the vector of integration not only at the political and economic level, but also culturally, especially in terms of economic culture. After all, globalization processes in the world have allowed many Ukrainians to feel the meaning of democratic values through working in companies with European capital, seeing the standard of living in EU countries and the freedom to build their nation without foreign imperial rule from other countries. By enshrining this desire in the Agreement on European Integration, the Ukrainian authorities have undertaken a number of commitments, fulfilling which will make it clear to the European community the seriousness of its intentions to cooperate and share the same democratic values.

The basis for creating conditions for life, meeting the needs of society and human is material culture, which is carried out through the economy. In this regard, we can talk about economic culture. At the same time, spiritual culture, the system of mental imperatives, moral values and social norms, in turn, determines the paradigm of society, as well as the level and type of economic culture. In addition, in every society there is an intellectual sphere - science, politics, philosophy. The connecting link between all these aspects of culture and at the same time the fundamental elements of culture are the values that are "rooted" in political, religious and economic relations.

In the early stages of human development, values were passed down from generation to generation, forming the mentality of the people. One of the most influential regulators of social life and the mechanism of mentality formation is religion. Religion arose and developed as a kind of value system that governs the relationship of Human with God, as well as Human with human. Public consciousness in the initial period of its development in an indivisible form included a religious element, which was "responsible" for the coordination of individual mentalities in accordance with the universal elements of life. A study of the impact of the Reformation showed that the starting point in the development of the system of economic categories may belong to religious knowledge, which forms the semantic level of 
existence. In this case, the "focus of the economist-theorist" is the "spirit of the economy - the problem of the evolution of the economic worldview of people as part of religion." $[6,7]$

Economic culture, as a projection of general culture on the system of economic life, creates for society economic values that affect the way of economic life and patterns of economic behavior. They, in turn, feel the impact of socio-cultural and socio-political situation, creating new socio-economic practices. The introduction of the concept of values - moral, religious, mental and national means a departure from the rigid deterministic concepts of individual behavior and development of society, perception and understanding of the idea of free choice as a condition of productive activity.

As a result of a complex "intertwining" of historical circumstances, which affected the "integrity" of the Orthodox consciousness, social structure of the population, binarity of the Ukrainian mentality, etc. formed by "natural selection" a certain type of economic culture that manifests itself in economic activity. [8]

Ukraine's economic culture was formed on the basis of paternalism, the consequences of which have a great influence on the present. Paternalism is defined as a system of established relations between the worker and the state, when in exchange for the employee's labor activity, the employee is given the opportunity to meet the minimum needs. The main features of paternalism include: state intervention in the decision-making process concerning the individual; this intervention is intended to promote the interests or well-being of the person, being protected; the intervention is carried out without the consent of the individual, being cared for. The paternalism of the state to the citizens is based on the concentration of resources in its hands, necessary for the livelihood and social protection of the population. This fact, in turn, allows the state to be subject to coercion. In the Soviet economy, such a concentration of resources was carried out primarily through the nationalization of industry, the deprivation of citizens of private ownership of the means of production, the denial of all kinds of private enterprise. [9]

The main features of the economic culture of paternalism were characteristics of communist countries, but so far they have significantly influenced modern democratic market transformations in post-communist countries, which is now observed in Ukraine: focus on patron-client relations: patron (goverment) offers its protection and provides dependent clients (citizens) with access to scarce resources. People could not earn many living benefits, but guaranteed employment, free education and health care, and a system of administrative regulation of prices reinforced the belief that they are taken care of. The minimalist labor strategy: the guarantee of the most important material goods determines the habit of insurance against extreme poverty, regardless of human economic activity (quantity and quality of work, skills, initiative, entrepreneurship), and at the level of mass consciousness, attitudes about social maintenance are formed. The equivalent psychology creates a willingness of people to voluntarily support the system of restrictions, a negative attitude to any form of entrepreneurship ("speculation"), the desire to block others from moving up, social envy. The value-rational nature of economic culture is embodied in ignoring the value of pragmatic assessments of human economic activity and in the absolutization of moral. Economic detraining as a cultural characteristic means the non-viability of the individual in other economic structures than paternalistic, the inability to implement independent economic strategies. The conservatism of paternalistic culture is manifested in its inability to quickly adapt to innovative trends, aimed at its enrichment and promoting the development of economic relations.

The phenomenon of post-Soviet economic culture, observed in Ukraine, cannot be included in the generally accepted typologies and classifications. It is characterized by a combination of several heterogeneous layers, elements that can be grouped into the following blocks: fragmentation, which is manifested in a combination of features of traditional Ukrainian, Soviet (paternalistic culture values) and modernist (capitalist culture values, borrowed from Western market institutions); the existence of many class, national, regional, religious and other subcultures; conflict - the lack of basic consensus in society on economic values, a high degree of tension between social and class groups; ambivalence, which is manifested in the simultaneous support of different economic values. The peculiarity of the value identification of modern Ukraine is that it is a European and Eurasian state in terms of civilization and culture. Ukrainian society is characterized by a stable and almost conflict-free coexistence of deep, but mostly repressed features of "Europeanness", and partly immanent, partly acquired in recent decades (imposed by the communist regime) "Eurasian" 
features. It should be noted, that Ukrainian Europeanness, at one time developed only in its initial and peripheral forms, and Soviet skills of socio-economic behavior and the corresponding system of economic values in a large part of the population were deeply rooted. [10]

The revolutionary events of 2014 deliberately made efforts to include Ukraine in the modernization process and reduced the gap between it and the Western world. This situation is due to the fact that the most powerful "selective system" of cultural approval is national factors, because the nation is the defining sphere of culture, including political, moral and, of course, economic.

The political, economic and socio-cultural transformations that have taken place in Ukraine in recent years have led to a significant transformation of the economic consciousness of the population. Studies of Ukraine's world values in 2020 show a very pronounced tendency to individualize values, weaken paternalistic attitudes, increase the focus on personal strength, and rationalize behavior. The result of these trends is an increase in the importance of individual responsibility and independence, the gradual erosion of the still quite strong paternalistic syndrome. Empirical studies of the seventh wave of WVS 2020 included questions on corruption, risk, migration, national security and law and order. About $60 \%$ of the questions are monitoring and recurring from the previous wave, while $40 \%$ of the questions are new. Also new for the seventh wave is the ability to monitor the implementation of a number of UN Sustainable Development Goals (SDGs), namely more than 100 indicator questions to monitor the following UN Sustainable Development Goals: 1 (overcoming poverty), 2 (overcoming hunger), 3 (healthy lifestyles and well-being), 4 (quality education), 5 (gender equality), 8 (employment and economic growth), 11 (sustainable urban and community development), 13 (climate change effects), 16 (peace, justice and strong institutions), 17 (global partnership).

Ukraine has clearly declared a European path of development, but according to the empirical data of WVS 2020, compared to the results of most EU countries, the value-regulatory system is one of the barriers in this direction.

Under the influence of social changes, the processes of transformation of Ukrainian society and economy, the value orientations in the field of labor, the attitude of the population to work in general and its individual aspects in particular are changing. (Table 1).Values in the economic sphere will affect the attitude to work, vision of mechanisms for ensuring the material well-being of workers and their families, the formation of personality and professional competencies, perception of social differentiation, wages, ownership, social guarantees, competition and more. [11]

Table 1

Survey of economic values of society

\begin{tabular}{|c|c|c|c|c|c|c|}
\hline Type of economic values & 1996 & 1999 & 2006 & 2008 & 2011 & 2020 \\
\hline Income equality vs larger income differences (average value on a 10-point scale) & 6.73 & 7.37 & 7.55 & 7.63 & 3.57 & 6.16 \\
\hline Private vs state ownership of business (average value on a 10-point scale) & 5.88 & 5.57 & 6.29 & 6.78 & 6.64 & 6.16 \\
\hline Government's vs individual's responsibility (average value on a 10-point scale) & 3.48 & 4.95 & 3.82 & 5.12 & 3.02 & 4.44 \\
\hline Competition good or harmful (average value on a 10-point scale) & 3.76 & 4.03 & 4.29 & 4.74 & 4.44 & 4.13 \\
\hline
\end{tabular}

Source: compiled by the authors according to: [11]

The departure from the equalization approach to the wage formation, which was typical in Soviet times, was reflected in the growing share of Ukrainians who supported the approach "income should be much higher in the case of more significant individual efforts." According to the results of the 2008-2020 survey, the average value changed from 7.63 to 6.16 , which shows the personal motivation of employees in receiving the amount of salary. In 2020, $47 \%$ supported this view, of which $18 \%$ chose the latest answer. The results in Ukraine are close to those of Sweden, Estonia and Bulgaria.

About $42 \%$ of Ukrainians tend to support the view that the share of state property in business and production should be increased (sum of answers from 7 to 10 points, $21 \%$ of respondents agreed with the opposite view that the share of private property in business and production should be increased) (sum of answers from 1 to 4 points) (Table 2). 
Table 2

Private vs state ownership of business breakdown by age

\begin{tabular}{ccccc}
\hline Question formulation & TOTAL (\%) & Up to 29 Age (\%) & $\mathbf{3 0 - 4 9}$ Age (\%) & 50 Age and more (\%) \\
\hline $\begin{array}{c}\text { 1- wich mean: "Private ownership of business } \\
\text { should be increased" }\end{array}$ & 4 & 6 & 3.9 & 3.4 \\
2 & 2 & 2.2 & 2.1 & 1.8 \\
3 & 5.5 & 6.7 & 5.4 & 5.1 \\
4 & 7.3 & 8.8 & 7.3 & 6.8 \\
5 & 20.1 & 21.8 & 21.6 & 18.2 \\
6 & 11.8 & 15.1 & 14.2 & 8.5 \\
7 & 11.7 & 13.6 & 12.3 & 8.5 \\
8 & 8.1 & 4.5 & 9.3 & 4.1 \\
9 & 3.3 & 2 & 3 & 18.2 \\
$10-$ wich mean : "Government ownership & 13.9 & 9.2 & 11.1 & 12.6 \\
of business should be increased" & 10.6 & 7.9 & 9.3 & 2.5 \\
Don't know & 1.6 & 2.2 & 0.5 & $\mathbf{5 6 5}$ \\
No answer & $\mathbf{1 . 2 8 9}$ & $\mathbf{1 8 8}$ & $\mathbf{5 3 5}$ & $\mathbf{6 . 0 4}$ \\
(N) & $\mathbf{6 . 1 7}$ & $\mathbf{5 . 6 3}$ & $\mathbf{2 . 3 2}$ & $\mathbf{2 . 3 8}$
\end{tabular}

Source: compiled by the authors according to: [11]

Ukrainians are the most supportive of state ownership in business and manufacturing, compared to other countries. The views of the inhabitants of Spain, Bulgaria and Poland are close.

The results also confirm the high level of paternalistic attitudes, which is decreasing very, very slowly - almost half ( $49.4 \%$ - the sum of answers from 1 to 4 points) to some extent share the view that the state should be more responsible for that all citizens are provided for. Instead, $22.4 \%$ supported the view that people themselves should be more responsible for providing for themselves (sum of answers from 7 to 10 points). Ukraine shows results close to Cyprus, Greece and Spain. The data also show a predominantly positive perception of competition. Ukraine's indicators are close to those of Finland, Greece, Italy, Lithuania and Slovenia (Table 3).

Based on the analysis of the Economic Freedom of the World 2019 report, we have made a number of important conclusions. Thus, in particular, Ukraine showed a certain growth in terms of business dynamism ( +1.9 points, 85 th place). This increase in the rating is due to the growth of the regulatory framework on insolvency and readiness for decentralization. In terms of innovation potential, the system of economic development of Ukraine shows a slight increase $\left(+1.1\right.$ points, $60^{\text {th }}$ place). This trend is primarily due to the improvement of the state of innovation clusters of the economy ( +3.6 points, 96th place), as well as the improvement of customer satisfaction ( +4.8 points, $65^{\text {th }}$ place) and so on. The analysis of the main components of the Global Competitiveness Index of Ukraine shows positive development trends, as most indicators have improved. However, compared to other countries, the overall score of Ukraine in the ranking remained unchanged.

Economic freedom is a fundamental right of every person to manage his or her own labor and property. In economically free societies, individuals are free to choose work, produce goods, spend, and invest in any way they wish. All these freedoms are supported and protected by the state. The fundamental basis of economic freedom is personal choice, voluntary exchange, freedom of market entry and competition, as well as the security of the individual and private property.

The Index, published in World Economic Freedom, measures the degree to which countries' policies and institutions support economic freedom. Forty-two indicators are used to construct the final index and measure the degree of economic freedom in five broad sectors. This dataset allows scholars to analyze the impact of both interstate differences in economic freedom and changes in 
their own freedom over three decades. Ukraine ranked 135th among 162 countries and territories, included in the report «Economic Freedom in the World - 2019». Note that the domestic economy still remains in an economically unfree group, along with countries such as Benin, Tajikistan, Mali, Pakistan and others. In terms of economic freedom, Ukraine remains at the level of 2010 and even in 2005. Over the past five years, positive changes have taken place in the area of regulatory trade barriers and in the regulation of the credit market. Negative dynamics is observed in the indicators of state ownership, growth of money supply and regulation of business in terms of administrative obligations, conditions for starting a business and licensing restrictions [12].

Table 3

Government's vs individual's responsibility breakdown by settlement type

\begin{tabular}{|c|c|c|c|c|c|c|}
\hline Question formulation & $\begin{array}{l}\text { TOTAL } \\
(\%)\end{array}$ & $\begin{array}{l}\text { Capital } \\
\text { city (\%) }\end{array}$ & $\begin{array}{c}\text { Regional } \\
\text { center }(\%)\end{array}$ & $\begin{array}{c}\text { District } \\
\text { center }(\%)\end{array}$ & $\begin{array}{c}\text { Another city, town (not a } \\
\text { regional or district center) (\%) }\end{array}$ & $\begin{array}{l}\text { Village } \\
(\%)\end{array}$ \\
\hline $\begin{array}{l}\text { 1- wich mean: "The government should } \\
\text { take more responsibility to ensure that } \\
\text { everyone is provided for" }\end{array}$ & 21.6 & 17.9 & 11.9 & 33.6 & 31.5 & 17.9 \\
\hline 2 & 5.8 & 5.7 & 6.6 & 5 & 7.2 & 5.3 \\
\hline 3 & 10.4 & 13.8 & 12.1 & 5.7 & 11.3 & 11.5 \\
\hline 4 & 9.8 & 8.1 & 11.8 & 8.1 & 7.8 & 10.3 \\
\hline 5 & 17.1 & 17.9 & 19.8 & 13.2 & 12.3 & 19.3 \\
\hline 6 & 10 & 4.9 & 12.6 & 9.1 & 9 & 10.1 \\
\hline 7 & 8.8 & 15.4 & 7.6 & 11.7 & 6.4 & 6.8 \\
\hline 8 & 4.6 & 8.1 & 6.3 & 5 & 3.5 & 2.6 \\
\hline 9 & 2.2 & 3.3 & 2.7 & 1.3 & 4.1 & 1.6 \\
\hline $\begin{array}{l}10 \text { - wich mean: "People should take more } \\
\text { responsibility to provide for themselves" }\end{array}$ & 6.1 & 4.9 & 6.8 & 6.3 & 4.5 & 6.1 \\
\hline Don't know & 2.7 & 0 & 1.7 & 0.3 & 1.6 & 6.1 \\
\hline No answer & 1 & 0 & 0 & 0.6 & 0.8 & 2.4 \\
\hline (N) & 1.289 & 96 & 320 & 319 & 125 & 429 \\
\hline Mean & 4.44 & 4.73 & 4.88 & 4.14 & 3.9 & 4.43 \\
\hline Std Dev. & 2.68 & 2.67 & 2.52 & 2.88 & 2.78 & 2.56 \\
\hline Base mean & 1.241 & 96 & 315 & 316 & 122 & 392 \\
\hline
\end{tabular}

Source: compiled by the authors according to [11]

World Bank experts annually compile a rating of «Doing Business», based on which you can analyze the state of business activity in the country, determine the ease of starting your own business and its further development within the economic system. According to the rating, in 2019 in Ukraine there is an improvement in business conditions, as a result of which the domestic economy increased its position by 7 points and took 64th place out of 190 .

Among the main transformations of the economic system that had an impact on doing business in 2019, World Bank experts include the following. Ukraine has streamlined construction permitting by eliminating the requirement to hire a manager from outside and introducing an online notification system, as well as making obtaining a building permit less expensive by reducing the fee. Ukraine has simplified the production of electricity by streamlining the issuance of technical conditions and the introduction of a geographic information system, as well as improved the implementation of energy supply by introducing a compensation mechanism for power outages. Ukraine has simplified property registration by increasing the transparency of the land management system. Ukraine has improved access to credit information by creating a new state register of loans with the National Bank of Ukraine [13]. Ukraine has strengthened the protection of minority investors, demanding greater disclosure of agreements with stakeholders. Ukraine is reducing the time of import, simplifying the requirements for certification of auto parts (Table 4).

The analysis of the presence of market barriers to entry and exit to the domestic market of Ukraine shows the stability of administrative barriers for businesses. In the ranking of 2019, positive changes are the reduction in the cost of registration procedures. The values of the indicators 
of the number of registration procedures and the duration of registration remain unchanged, which indicates the need to develop procedures to reduce the level of administrative barriers to entry for businesses in the domestic market of Ukraine.

Table 4

Indicators of barriers to entry into the domestic market of Ukraine

\begin{tabular}{cccccc}
\hline Indicator of the barrier to entry into the domestic market & $\mathbf{2 0 1 5}$ & $\mathbf{2 0 1 6}$ & $\mathbf{2 0 1 7}$ & $\mathbf{2 0 1 8}$ & $\mathbf{2 0 1 9}$ \\
\hline Number of registration procedures & 5 & 6 & 6 & 6 & 6 \\
Duration of registration, days & 8 & 6.5 & 6.5 & 6.5 & 6.5 \\
Cost of registration procedures, \% of per capita income & 1.1 & 0.9 & 0.8 & 0.6 & 0.5 \\
Minimum mandatory authorized capital, \% of per capita income & 0.0 & 0.0 & 0.0 & 0.0 & 0.0 \\
The average duration of the procedure & 2.9 & 2.9 & 2.9 & 2.9 & 2.9 \\
The value of sunk costs, \% of value & 40.5 & 40.5 & 40.5 & 40.5 & 40.5 \\
Debt repayment ratio, cents up to 1 US dollar & 9.3 & 8.4 & 8.9 & 9.6 & 9 \\
Index of efficiency of the regulatory framework & 8.5 & 8.5 & 8.5 & 8.5 & 8.5
\end{tabular}

Source: compiled by the authors according to: [13]

The values of irrecoverable costs (as a percentage of the value of real estate) are still high $-40.5 \%$, as well as the average duration of bankruptcy proceedings -2.9 , The negative dynamics is observed in the debt repayment rate, which, moreover, is much lower than among OECD member countries. The study gives grounds to draw conclusions about the further need to improve the conditions for entry and exit from the domestic market. The existence of such a level of administrative barriers requires a comprehensive action plan of the executive branch, aimed at establishing the minimum possible conditions for doing business and ensuring competitive conditions. Implementation of these actions will create a basis for attracting potential investors to Ukraine. The study of the state and trends of the competitive environment in Ukraine allows us to conclude that the competitive environment is the basis for the effective functioning of national markets. Therefore, the analysis and assessment of its development provides an opportunity to respond effectively to changes at the state level. Analyzing the results of business assessments, it was determined that traditionally in Ukraine domestic competition between resident enterprises prevails over competition from foreign companies. This trend naturally continued in 2018-2019.

Thus, the share of those respondents, who noted a high level of competition in the markets for their products, compared to Ukrainian companies, was about twice the share of businesses that noted a high level of competition in the markets for their products, compared to foreign companies. A significant level of competition in the domestic markets was noted in 2019 by the heads of enterprises of such major economic activities as food production, agriculture, hunting and related services, etc.

Regarding the level of competition with foreign companies, it should be noted a significant decrease in the share of respondents, who indicated the lack of competition (almost twice). At the same time, it should be noted, that almost $40 \%$ of the surveyed business leaders admitted that they could not determine the level of competition, compared to foreign companies, which may indicate that such respondents did not experience significant competition in the markets of their main products, compared to companies of foreign states, due to its absence. The lack of competition in the markets for their main products, compared to foreign countries, was noted by the heads of enterprises of such major economic activities as health care and social assistance, collection, cleaning and supply.

Still high are the values of sunk costs (as a percentage of the value of real estate) $-40.5 \%$, as well as the average duration of bankruptcy proceedings - 2.9. The negative dynamics is observed in the debt repayment rate, which, moreover, is much lower than among OECD member countries. The study gives grounds to draw conclusions about the further need to improve the conditions for entry and exit from the domestic market. The existence of such a level of administrative barriers requires a comprehensive action plan of the executive branch, aimed at establishing the minimum possible conditions for doing business and ensuring competitive conditions. Implementation of these actions will create a basis for attracting potential investors to Ukraine. The study of the state and trends of the competitive environment in 
Ukraine allows us to conclude that the competitive environment is the basis for the effective functioning of national markets. Therefore, the analysis and assessment of its development provides an opportunity to respond effectively to changes at the state level. Analyzing the results of business assessments, it was determined, that traditionally in Ukraine domestic competition between resident enterprises prevails over competition from foreign companies. This trend naturally continued in 2018-2019.

Thus, the share of those respondents, who noted a high level of competition in the markets for their products, compared to Ukrainian companies was about twice the share of businesses that noted a high level of competition in the markets for their products, compared to foreign companies. A significant level of competition in the domestic markets was noted in 2019 by the heads of enterprises of such major economic activities as food production, agriculture, hunting and related services, etc.

Regarding the level of competition with foreign companies, it should be noted a significant decrease in the share of respondents, who indicated the lack of competition (almost twice). At the same time, it should be noted, that almost $40 \%$ of the surveyed business leaders admitted that they could not determine the level of competition, compared to foreign companies, which may indicate that such respondents did not experience significant competition in the markets of their main products, compared to companies of foreign states, due to its absence. The lack of competition in the markets of their main products, compared to foreign countries, was noted by the heads of enterprises of such major economic activities as health care and social assistance, collection, purification and supply of water, electricity, gas, steam and air conditioning, retail, in addition to trade in motor vehicles and motorcycles [13].

The main limitations in this study were the sample data when polling the economic opinions and sentiments of the population, which can give a deviation, but did not affect the dynamics or trend in general. The prospects for further research into the influence of the economic culture of society on the process of transformation and integration into the European one are very relevant and require further refinement, in particular, the economic values of government officials and those, who make decisions on the distribution of budgets.

\section{Conclusions}

Thus, having studied the economic culture in the European integration process, the identified state shows permanent heterogeneity, antimony, ambivalence and it must be considered in the plane of transformational processes of society's values. Contradictions in the formation of culture are due to the process of formation and development of economic freedoms and changes in values of the population of Ukraine. The formation of economic freedoms is correlated with rising living standards and personal responsibility of citizens for their struggle. The transformation process shows a gradual change in society's views from traditional values - to secular, rational, despite the non-cessation of existential threats in eastern Ukraine. In contrast, there is another process, which is accompanied by a decrease in tolerance, a decline in confidence in state institutions, and a sharpening of materialist and self-realization values.

European integration, which significantly accelerates the transformation of national economic cultures into globalization, democracy, on the verge of 2020 received the opposite movement, a rollback and a return to the left. Eastern European countries, including Ukraine, due to the context of historical formation are extremely vulnerable to this movement - the rejection of democratic freedoms, and a return to archaic practices in various variations. The application of the WVS values research model $[14,15]$ makes it possible to identify significant trends in the value orientations of society in more than 100 countries, for the period 1990-2020. The analysis of the data shows value changes in the countries that have joined the process of European integration, and significantly accelerated the rate of economic growth, compared to countries in a state of economic transformation, or, conversely, the refusal to fight for economic freedoms, which allows to establish a correlation between the level of national economic culture, economic development, economic sustainability and transformation in the face of growing unpredictable threats.

According to the 7th wave of the WVS survey, Ukrainians feel more prosperous, which indicates an increase in the well-being of the population and a sense of existential security, which in general helps to increase democratic freedoms (economic freedoms in particular) and the formation of state institutions. At the same time, the progressive economic crisis, caused by the pandemic, 
unsystematic social policies, declining confidence in the executive branch, and ineffective management decisions to prevent and combat COVID-19 are the foundations for anti-European integration processes, in terms of values.

Thus, summarizing the results of the study of economic culture in the European integration process, it should be noted its transformational state, and the possibility of significant variations, given the historical and political context and the course of changes in values in society.

Although the economic and political vector of integration development for Ukraine remains in the direction of Europe, with democratic state institutions and an effective strategy of economic development, transparent conditions of public administration, the mood towards a return to materialistic values of society is growing significantly. The analysis provides an opportunity to understand the value context of change in the countries of the European integration process, and to identify threats to slow down and suspend this movement. This, in turn, helped to supplement the socio-cultural and economic dimensions of the transformation of economic culture, as well as to outline Ukraine's place in the regional context and assess the prospects and obstacles to its development on the path to European integration.

\section{References}

[1] Lagytin, V. (2019). Civilizational and institutional factors of global economic transformations of the XXI century. Foreign trade: economics, finance, law, 2, 6-19. doi: http://doi.org/10.31617/zt.knute.2019(103)01

[2] Müller, K. (1992). "Modernizing” Eastern Europe: Theoretical problems and political dilemmas. European Journal of Sociology, 33 (1), 109-150. doi: http://doi.org/10.1017/s000397560000638x

[3] Tiryakian, E. A.; Grancelli, B. (Ed.) (1995). Modernization in a millenarian decade: Lessons for and from Eastern Europe. Social change and modernization: Lessons from Eastern Europe. Berlin: Walter de Gruyter, 249-264. doi: http://doi.org/ 10.1515/9783110884470.249

[4] Cohen, S. F. (2001). Failed crusade: America and the tragedy of post-communist Russia. New York: W. W. Norton \& Co, 366.

[5] Savelyev, Y. (2019). Inclusive modernization and contradictions of changes in value systems of Eastern European countries in the 1990s and 2000s. Sociology: Theory, Methods, Marketing, 2, 70-97. doi: http://doi.org/10.15407/sociology2019.02.070

[6] Kistersky, L. (2018). Prerequisites of social and solidarity economy development in Ukraine. Economy of Ukraine, 5 (678), 85-88. Available at: http://nbuv.gov.ua/UJRN/EkUk_2018_5_8

[7] Smit, V. L.; Sheremeta, R., Romanenko, O. (Eds.) (2017). Reformation: the Success of Europe and a Chance for Ukraine. Kyiv: Sammit-Kniga, 256.

[8] Umantsiv, Y., Urbanovich, V. (2020). Macroeconomic dimension of fiscal policy in the context of the global crisis. Geopolitics of Ukraine: history and modern times, 1, 122-123. doi: http://doi.org/10.24144/2078-1431.2020.1(24).119-131

[9] Butkaliuk, V. (2020). Inequality in the context of economic globalization: the empirical sociological dimension. Sociology: Theory, Methods, Marketing, 1, 66-85. doi: http://doi.org/10.15407/sociology2020.01.066

[10] Romanenko, O. (2013). The analysis of the impact of the economic culture of Ukraine on the integration process with EU. Current issues of international relations, 116.

[11] WVS/EVS Joint 2017. WVS Database. Available at: http://www.worldvaluessurvey.org/WVSEVSjoint2017.jsp Last accessed: 10. 12.2020

[12] Economic Freedom of the World 2019. Annual report. Avaleble at: https://ueff.org/images/UEFF/content/indices/fraser/economic-freedom-of-the-world-2019.pdf

[13] Doing Business. Comparing Business Regulation in 190 Economies. Avaleble at: https://openknowledge.worldbank.org/bitstream/handle/10986/32436/9781464814402.pdf Last accessed: 10. 12.2020

[14] Inglehart, R., Welzel, Ch. (2005). Modernization, cultural change and democracy: The human development sequence. New York: Cambridge University Press. doi: http://doi.org/10.1017/cbo9780511790881

[15] Inglehart, R., Welzel, Ch. (2010). Changing mass priorities: The link between moder - nization and democracy. Perspectives on Politics, 8 (2), 551-567. doi: http://doi.org/10.1017/S1537592710001258 